\title{
THE ETVIEW TRACHEOSCOPIC VENTILATION TUBE FOR TRAUMA PATIENT INTUBATION
}

\author{
Marcin Madziala
}

Lazarski University, Warsaw, Poland

Disaster Emerg Med J 2018; 3(2): 69-70

Sir,

We read the article by M. Ladny [1] with great interest. The authors discuss the extremely important problem of intubating a patient who has a difficult access to the airways. It is worth highlighting that injuries are currently one of the main challenges that medical staff has to face [2-4]. In traumatic patients, one of the main causes of cardiac arrest is the inability to maintain an airway patency which leads to deep hypoxia and subsequently to cardiac arrest. This is especially common in patients with cranio-cerebral trauma [5]. The ability to maintain the airway patency in trauma patients is therefore a key element of emergency proceedings as it may cause the deep hypoxia and subsequently the cardiac arrest. However, the efficacy of securing the airway patency with the usage of an intubation tube performed with direct laryngoscopy is insufficient in the conditions where the emergency medicine operates [6-8]. In order to improve the efficacy in the aforementioned conditions, we should focus on researching new, more effective methods of endotracheal intubation, which should increase the effectiveness of the first intubation attempt and shorten the time of the procedure.

The aim of the study was to evaluate the effectiveness of intubation with the use of the ETView tracheoscopic ventilation tube vs. standard Macintosh laryngoscope in conditions of immobilization of the cervical spine.

In order to simulate a patient requiring endotracheal intubation, a Resusci Anne simulator (Laerdal, Norway) was used. It was secured to a spinal board with side head stabilizers and additionally the Patriot neck collar (Össur Americas, USA) was attached to it. The study utilized two types of laryngoscopes: The Macintosh standard laryngoscope with blade no. 3 (Gima S.p.A., Italy) and the ETView tracheoscopic ventilation tube (ETView Ltd, Israel; Fig. 1). For each intubation method endotracheal tube with 7.0 internal diameter were used. In order to standardize the participants' knowledge, similarly to other $[4,9,10]$ studies, a short training in the use of ETVIEW direct laryngoscopy and videolaryngoscopy was performed just prior to the study. After theoretical part, the participants had practical training in performing endotracheal intubation utilizing both techniques ( $5 \mathrm{~min}$ for each device) on normal airway. Both the order of participants and endotracheal intubation methods were randomized with the coin toss technique.

The study included 52 nurses, with mean age of $32.5 \pm 8.5$ years, and mean work experience of $8 \pm 4.5$ years. All participants declared having knowledge and skills with direct laryngoscopy prior to the study. The effectiveness of the first intubation attempt for the Macintosh laryngoscope was 34.6\%

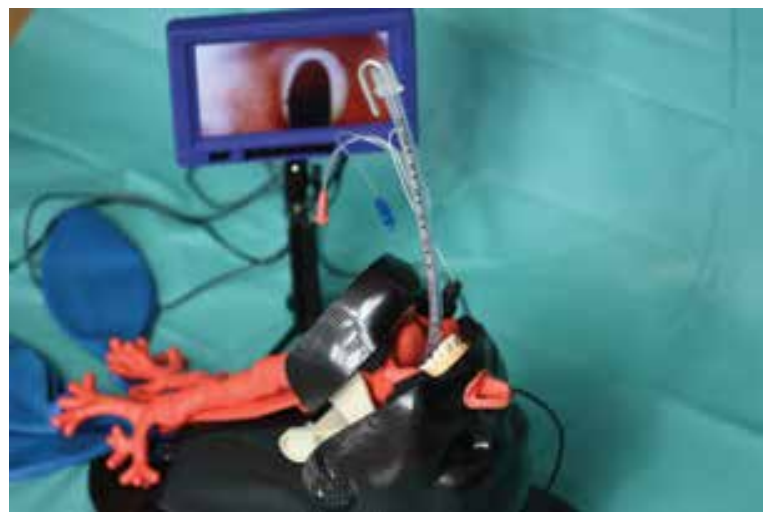

FIGURE 1. Endotracheal intubation using ETView SL 
vs. $90.4 \%(p<0.01)$ for ETView. The time of performing the procedure of intubation with the use of Macintosh laryngoscope and ETView varied and amounted for $48.5 \pm 9.5$ vs. $24 \pm 12.2$ seconds $(p<0.01)$, respectively. Study participants assessed the degree of glottic visualization on a 100-point scale. For the Macintosh laryngoscope this parameter amounted for $34 \pm 8$ points vs. $90 \pm 8$ points for ETView $(p<0.01) .100 \%$ of participants in the study chose ETView as a method of choice of intubation during in real life rescue operations.

To sum up, the effectiveness of direct laryngoscopy is insufficient in this simulation study. The ETView tracheoscopic ventilation tube, when compared with the Macintosh laryngoscope allows for the higher efficiency of the first intubation attempt and shortens the time of the procedure.

Conflict of interest: None declared.

\section{REFERENCES}

1. Ladny M, Smereka J, Szarpak L, et al. Assessment of the cervical collar application impact on the conditions of intubation and the feelings of patients - pilot study. Disaster Emerg Med J. 2018; 3(1): 1-4, doi: 10.5603/DEMJ.2018.0001.

2. Smereka J, Ladny JR, Naylor A, et al. C-MAC compared with direct laryngoscopy for intubation in patients with cervical spine immobilization: A manikin trial. Am J Emerg Med. 2017; 35(8): 1142-1146, doi: 10.1016/j.ajem.2017.03.030, indexed in Pubmed: 28341185.

3. Jain NB, Ayers GD, Peterson EN, et al. Traumatic spinal cord injury in the United States, 1993-2012. JAMA. 2015; 313(22): 2236-2243, doi: 10.1001/jama.2015.6250, indexed in Pubmed: 26057284.
4. Szarpak L, Truszewski Z, Kurowski A, et al. Tracheal intubation with a VivaSight-SL endotracheal tube by paramedics in a cervical-immobilized manikin. Am J Emerg Med. 2016; 34(2): 309-310, doi: 10.1016/j. ajem.2015.10.013, indexed in Pubmed: 26597329.

5. Szarpak L, Madziala M. Epidemiology of cranio-cerebral injuries in emergency medical services practice. Pol Przegl Chir. 2011; 83(12): 646-651, doi: 10.2478/v10035-011-0103-8, indexed in Pubmed: 22343200.

6. Ladny JR, Smereka J, Szarpak L. Comparison of the Trachway video intubating stylet and Macintosh laryngoscope for endotracheal intubation. Preliminary data. Am J Emerg Med. 2017; 35(4): 574-575, doi: 10.1016/j.ajem.2016.12.015, indexed in Pubmed: 27986336.

7. Szarpak L, Truszewski Z, Czyzewski L, et al. A comparison of the McGrath-MAC and Macintosh laryngoscopes for child tracheal intubation during resuscitation by paramedics. A randomized, crossover, manikin study. Am J Emerg Med. 2016; 34(8): 1338-1341, doi: 10.1016/j. ajem.2015.11.060, indexed in Pubmed: 26712571.

8. Truszewski Z, Szarpak L, Smereka J, et al. Comparison of the VivaSight single lumen endotracheal tube and the Macintosh laryngoscope for emergency intubation by experienced paramedics in a standardized airway manikin with restricted access: a randomized, crossover trial. Am J Emerg Med. 2016; 34(5): 929-930, doi: 10.1016/j. ajem.2016.02.054, indexed in Pubmed: 26979260.

9. Karczewska K, Szarpak L, Smereka J, et al. ET-View compared to direct laryngoscopy in patients with immobilized cervical spine by unexperienced physicians: A randomized crossover manikin trial. Anaesthesiol Intensive Ther. 2017; 49(4): 274-282, doi: 10.5603/AlT.a2017.0047, indexed in Pubmed: 28953308.

10. Stawicka I, Czyzewski L, Smereka J, et al. Comparison of four laryngoscopes for orotracheal intubation by nurses during resuscitation with and without chest compressions: a randomized crossover manikin trial. Disaster Emerg Med J. 2016; 1(1): 14-23, doi: 10.5603/ DEMJ.2016.0003. 